\title{
Uso de canabidiol como terapia adjuvante em paciente com síndrome de Zellweger: relato de caso
}

\author{
Cannabidiol as adjuvant therapy in a patient with Zellweger syndrome: a case report \\ Samilly Oliveira ${ }^{1}$ (D) Elias Machado ${ }^{1}$ (D), Fabrício Fóla ${ }^{1}$ (D), Zumira Aparecida Carneiro² (D), \\ Charles Marques Lourenço ${ }^{3}$ (D)
}

\begin{abstract}
RESUMO
Também denominada síndrome cerebrohepatorenal, a síndrome de Zellweger é uma doença autossômica recessiva rara, pertencente ao espectro de erros inatos do metabolismo que afetam os peroxissomos. São causados principalmente por mutações em qualquer um dos 14 genes PEX diferentes que codificam para proteínas envolvidas na montagem do peroxissoma, sendo a mais comum do PEX1. O quadro clínico geralmente é observado no período neonatal e primeira infância, incluindo alterações faciais, hipotonia profunda e ausência de reflexos neonatais, além de disfagia, disfunção hepática e convulsões. O diagnóstico é feito a partir da clínica e testes bioquímicos e confirmados pela visualização da mutação em um dos 14 genes PEX. Como não há tratamento específico, é feito tratamento sintomático. Nosso paciente masculino de 1 ano e 9 meses apresentou a hipotonia congênita como sintoma marcante, além de crises convulsivas recorrentes logo após o nascimento. Evoluiu com necessidade de gastrostomia e estagnação de marcos neuromotores. O diagnóstico foi confirmado aos seis meses, através da dosagem de ácidos graxos de cadeia longa. Crises convulsivas evoluíram de maneira refratária a diversos anticonvulsivantes e com elevada frequência diária, por isso iniciamos canabidiol (CBD-RSHO GOLD) por via enteral que reduziu significantemente as crises. Não há tratamento definitivo para esta enfermidade, sendo importante tratamento sintomático das crises convulsivas e terapias de reabilitação, nesse caso, o uso de (CBD- RSHO GOLD) provocou uma redução de $92 \%$ na frequência de crises diárias do paciente. No entanto, não é possível concluir, ainda, melhoras em outros sinais e sintomas.
\end{abstract}

Palavras-chave: Síndrome de Zellweger; Peroxinas; Epilepsia; Canabidiol.

\begin{abstract}
Also referred to as "brain-liver-kidney" syndrome, the Zellweger syndrome is a rare autosomal recessive disorder, belonging to the spectrum of inborn errors of metabolism that affect peroxisomes. They are caused mainly by mutations in any of the 14 different PEX genes that code for proteins involved in the assembly of peroxisome, being the most common of PEX1. The clinic is usually observed in the neonatal and early childhood period, including facial changes, deep hypotonia, and absence of neonatal reflexes in childhood, in addition to dysphagia, hepatic dysfunction, and seizures. The diagnosis is made from clinical and biochemical tests and confirmed by the visualization of the mutation in one of the 14 PEX genes. Since there is no specific treatment, symptomatic treatment is done. Our 1-year and 9-month-old male patient presented congenital hypotonia as a striking symptom in addition to recurrent seizures shortly after birth. It evolved with the need for gastrostomy and stagnation of neuromotor frames. The diagnosis was confirmed at six months by the measurement of long-chain fatty acids. Convulsive seizures evolved in a manner that was refractory to several anticonvulsants and with a high daily frequency, so we initiated cannabidiol (CBD-RSHO GOLD) by an enteral route that significantly reduced the seizures. Since there is no available treatment for seizures, in this case, the use of CBD-RSHO GOLD reduced by $92 \%$ the daily seizure frequency. However, it is not possible to conclude further improvements in other signs and symptoms.
\end{abstract}

Keywords: Zellweger Syndrome; Peroxins; Epilepsy; Cannabidiol.

1. Acadêmicos do curso de Medicina do Centro Universitário Estácio de Ribeirão Preto, Ribeirão Preto (SP), Brasil.

2. Farmacêutica, Profa. titular do curso de Medicina do Centro Universitário Estácio de Ribeirão Preto, Ribeirão Preto (SP), Brasil.

3. Médico Geneticista, Prof. titular do curso de Medicina do Centro Universitário Estácio de Ribeirão Preto, Ribeirão Preto (SP), Brasil.

$\triangle$ Charles Marques Lourenço. Centro Universitário Estácio de Ribeirão Preto. Rua Abrahão Issa Halach, 980 - Ribeirânia. CEP: $14096-160$. Ribeirão (SP), Brasil.

charlesgenetica@gmail.com | Recebido em: 19/10/2019 | Aprovado em: 13/03/2020 


\section{INTRODUÇÃO}

A síndrome de Zellweger é uma doença autossômica recessiva rara, representando a forma mais extrema do espectro de erros inatos do metabolismo que afeta os peroxissomos, e pode também ser denominada síndrome cerebrohepatorenal ${ }^{1}$. Esse distúrbio na síntese dos peroxissomos interfere na $\beta$-oxidação de ácidos graxos de cadeia muito longa (AGCML), síntese de ácidos biliares, a-oxidação de ácidos graxos, desintoxicação de glioxilato e/ou degradação de ácido L-pipecólico².

Os distúrbios da biogênese dos peroxissomos são causados principalmente por mutações em qualquer um dos 14 genes PEX diferentes que codificam para peroxinas, proteínas envolvidas na montagem do peroxissoma. Mutações no PEX1 são responsáveis por aproximadamente $70 \%$ de todos os casos de síndrome de Zellweger, os demais casos (26\%) são causados por mutações em PEX6, PEX10, PEX12 ou PEX $26^{3}$. Defeitos em genes humanos que codificam proteínas peroxissômicas podem resultar em distúrbios peroxissômicos diferentes com gravidade variável, variando de letalidade precoce a sutis aberrações neurossensoriais ${ }^{4}$.

Trata-se de uma doença usualmente progressiva e fatal. Suas características clínicas são geralmente observadas no período neonatal e primeira infância, incluindo alterações faciais (fronte elevada, aumento da ponte nasal, epicanto, fissuras palpebrais metópicas amplamente abertas, cristas supra orbitais subdesenvolvidas, boca triangular e orelhas de formato baixo), hipotonia profunda e ausência de reflexos neonatais na infância, além de disfagia, disfunção hepática e convulsões. Apresentam alterações laboratoriais como hiperbilirrubinemia, hipertransaminasemia, coagulopatias e anatômicas como hepatomegalia. Dentre as alterações neurológicas podemos encontrar disgenesia cerebral, hipomielinização difusa (síntese qualitativa anormal de mielina) e degeneração neurossensorial, as convulsões são uma das apresentações mais evidentes da doença cerebral ${ }^{5}$.

O diagnóstico dessa síndrome é estabelecido através das características clínicas sugestivas, testes bioquímicos (análise de ácidos graxos de cadeia muito longa (AGCML), dosagem dos ácidos pristânico, fitânico, pipecólicos e biliares), análise da síntese de plasmalógenos detectada nas hemácias confirmadas pela cultura de fibroblastos, exames de imagem (RNM), e confirmado pela detecção de mutações em um dos 14 genes PEX ${ }^{6}$.

Não existe tratamento curativo para essa síndrome, sendo o tratamento, essencialmente, sintomático. Podem ser utilizados anticonvulsivantes e vitamina $\mathrm{K}$ para melhorar transtornos hemorrágicos decorrentes da hepatopatia. Deve-se limitar o consumo de gorduras insaturadas e ácido fitânico. Além disso, em virtude de ser uma enfermidade de herança autossômica recessiva, aconselhamento genético é recomendado para os genitores ${ }^{3}$.

Relatamos caso de paciente diagnosticado com síndrome de Zellweger por mutação no gene PEX1 e abordagem terapêutica com uso de canabidiol para tratamento de epilepsia de difícil controle associada a essa enfermidade. Neste relato, os dados foram obtidos através da revisão do prontuário com a autorização do comitê de ética do hospital e do paciente, obtida por assinatura do termo de consentimento livre e esclarecido.

\section{RELATO DE CASO}

Paciente do sexo masculino, 1 ano e 9 meses, segundo filho de casal jovem e não consanguíneo, foi encaminhado para avaliação de hipotonia congênita.

Paciente nasceu de parto cesariano, a termo, após uma gestação sem intercorrências. Apresentou peso ao nascimento de $3170 \mathrm{~g}$ (p25-p50) e estatura de $53 \mathrm{~cm}(\mathrm{p} 90)$, perímetro cefálico $(P C)$ de $35 \mathrm{~cm}$, adequado para idade (p75 - p90) e perímetro torácico (PT) de 32cm (p50 - p75).

Logo após o nascimento, apresentou crises convulsivas frequentes, hipotonia acentuada foi observada nos primeiros dias de vida, além de ausência do reflexo de Moro e do reflexo de fuga à asfixia. Obteve alta para prosseguir com investigação diagnóstica, visto possuir irmã mais velha já falecida com quadro similar, mas sem diagnóstico estabelecido à época.

Ao exame físico, paciente apresentava dimorfismos craniofaciais (hipertelorismo, elevação da fronte e epicanto pronunciado) que foram se acentuando no decurso da doença (Figura 1), além de grave hipotonia global com presença de reflexos osteotendíneos hiperativos. É capaz de seguir objetos com o olhar, prestando atenção ao examinador. 

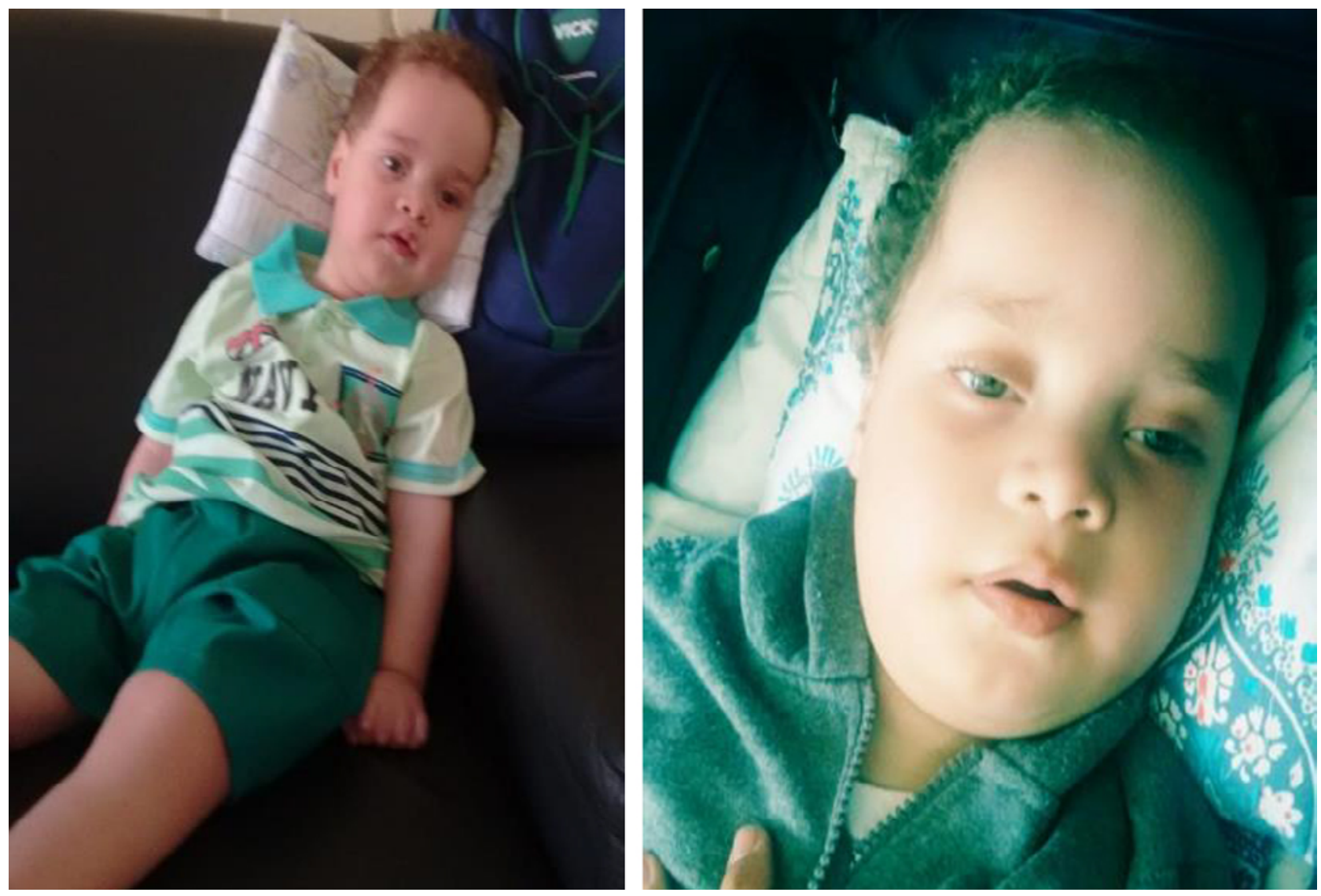

Figura 1: Paciente do presente caso com síndrome de Zellweger. Postura hipotônica (A). Observe os traços faciais característicos descritos anteriormente (B). Acervo pessoal dos pesquisadores.

Fonte: Os Autores (2019).

Não há outros familiares com sintomas semeIhantes, com exceção de irmã do paciente, mencionada previamente.

Paciente evoluiu com disfagia progressiva, sendo necessário gastrostomia. Apresentou, ainda, estagnação de marcos motores (não possui sustento cefálico ou de tronco, não emite palavras, apenas vocaliza alguns sons).

Para elucidar a causa da hipotonia, eletroneuromiografia foi realizada no primeiro mês de vida e, após primeiro resultado duvidoso, a repetição do exame evidenciou padrão central de hipotonia, corroborando a hipótese de desmielinizarão central.

Foi realizada ressonância nuclear magnética do encéfalo do paciente aos seis meses, sendo possível visualizar, em corte sagital, diminuição da espessura do corpo caloso, além de ventrículos laterais com moderada dilatação, substância branca em grande parte hipomielinizada, displasia cortical, especialmente na região da fissura Silvyana bilateral, com presença de polimicrogiria, além de pseudocistos subependimários em núcleo caudado bilateralmente. Esses achados, em conjunto com apresentação clínica do paciente, eram bastante sugestivos de doença peroxissomal em fase inicial, porém não eram características de uma doença peroxissomal específica.

O diagnóstico foi confirmado aos seis meses de vida da criança, através da dosagem de ácidos graxos de cadeia longa, evidenciando aumento dos AGCML e demonstrando perfil compatível com doença peroxissomal (Tabela 1). Para elucidação do subtipo de doença peroxissomal, solicitou-se painel de genes para doenças peroxissomais cujo resultado evidenciou as mutações c.3517 (p. Q1173X) e c.273G>A (p. Q91X) no gene PEX 1, confirmando-se o diagnóstico bioquímico e clínico. 
Tabela 1

Análise de ácidos graxos de cadeia muito longa

\begin{tabular}{lcc}
\hline AGCML & Resultados & $\begin{array}{c}\text { Valores de } \\
\text { Referência }\end{array}$ \\
\hline C26:0 $(\mu \mathrm{M} / \mathrm{L})$ & 2,5 & $0,53(0,11-0,96)$ \\
Relação C24:0/C22:0 & 0,94 & $0,94(0,78-1,09)$ \\
Relação C26:0/C22:0 & 0,08 & $0,02(0,008-0,03)$ \\
\hline
\end{tabular}

Fonte: Os Autores (2019).

Crises convulsivas do paciente evoluíram de maneira refratária a diversos anticonvulsivantes, ocorrendo em grande frequência diária. Mesmo em uso de fenobarbital, levetiracetam e ácido valproico, ainda exibe em torno de vinte e cinco crises convulsivas diárias. Diante da dificuldade em controlar as crises, foi iniciado uso de canabidiol (CBD- RSHO GOLD), associado aos anticonvulsivantes já utilizados. Instituído na posologia de 2,4 $\mathrm{cm}$ de canabidiol diluído em azeite extravirgem, administrado por via enteral (gastrostomia), uma vez ao dia; não houve efeitos colaterais associados ao medicamento e paciente apresentou boa aceitação via sonda. Após quatro meses de tratamento com canabidiol (sem modificar demais anticonvulsivantes), número de crises reduziu para duas crises diárias.

\section{Tabela 2}

Anticonvulsivantes em uso pelo paciente.

\begin{tabular}{lc}
\hline Medicamento & Posologia \\
\hline Fenobarbital $(40 \mathrm{mg} / \mathrm{ml})$ & $3,4 \mathrm{mg} / \mathrm{Kg} / \mathrm{dia}$ \\
Levetiracetam $(100 \mathrm{mg} / \mathrm{ml})$ & $11 \mathrm{mg} / \mathrm{Kg} / \mathrm{dia}$ \\
Ácido Valproico $(250 \mathrm{mg} / \mathrm{ml})$ & $37 \mathrm{mg} / \mathrm{Kg} / \mathrm{dia}$ \\
\hline Fonte: Os Autores $(2019)$. &
\end{tabular}

\section{DISCUSSÃO}

Os peroxissomos são organelas necessárias para diversas funções metabólicas como degradação de ácidos graxos de cadeia muito longa, síntese de ácidos biliares, produção de plasmalógenos, entre outros ${ }^{7}$.

Existem situações na qual alguns indivíduos apresentam disfunção nessa organela podendo ser divididas em dois grupos distintos: doenças provocadas pela deficiência de uma única enzima peroxissomal e doenças da biogênese peroxissomal
(DBP), apresentando, por conseguinte, diferentes características fenotípicas ${ }^{4}$.

O conjunto de doenças devido à deficiência de uma enzima única peroxissomal envolve a condrodisplasia rizomélica punctata (CDRP) tipo 2 na qual se tem ausência de produção de plasmalógenos e as características clínicas típicas compreendendo convulsões, catarata congênita e retardo de crescimento. Além disso, alguns indivíduos apresentam deficiência de uma enzima da $\beta$-oxidação peroxissomal de ácidos graxos de cadeia muito longa desenvolvendo a Adrenoleucodistrofia associada ao cromossomo $\mathrm{X}$, caracterizada por degeneração progressiva do SNC e glândula adrenal ${ }^{8}$.

As DBP são provocadas pela deficiência de peroxinas, proteínas responsáveis pela manutenção dos peroxissomos, e são classificadas em dois grupos, o espectro de Zellweger (EZ) (Síndrome de Zellweger, adrenoleucodistrofia neonatal, doença infantil de Refsum) causado por mutações nos genes PEX1, 2, 3, 5, 6, 10, 11B, 12, 13, 14, 16, 19, 26 , e a condrodisplasia rizomélica punctata tipo 1 (CDRP1) causada por mutação do gene PEX $7^{10}$.

As manifestações do EZ são heterogêneas, mas geralmente graves, sendo a síndrome de Zellweger a forma mais devastadora do espectro. Descrita inicialmente em 1964, suas características clínicas típicas incluem dismorfias craniofaciais (fonte alta, fontanela ampla, palato ogival, nariz achatado, epicanto, deformidades dos lóbulos das orelhas), disfunções do SNC (microgiria, displasias corticais, convulsões), severa hipotonia9 ${ }^{9}$. As manifestações clínicas do nosso paciente sugerem um erro inato do metabolismo, apresentando fenótipo sugestivo dessa síndrome (Tabela 3 ).

No caso, após a suspeita pelas manifestações clínicas de desordens peroxissomais, seu diagnóstico foi confirmado através da dosagem de ácidos graxos de cadeia longa e teste genético evidenciando mutação no gene PEX1. As mutações mais comuns estão no PEX1, que codifica a peroxina 1, sendo responsável por dois terços de todos os pacientes com Zellweger. No entanto, em muitas situações apesar de os recém-nascidos apresentarem tais manifestações clínicas, não é feito diagnóstico correto. Dentre os motivos, vale ressaltar que as características clínicas de distúrbios metabólicos hereditários como hipotonia, convulsões, acidose láctica são muito semelhantes a encefalopatia hipóxico-isquêmica e sepse, que são condições 
clínicas mais frequentes, dessa forma, caso o médico não realize uma investigação ativa para distúrbios metabólicos hereditários, a criança será tratada erroneamente apenas pela sintomatologia e sua doença de base, hereditária, resultando, muitas vezes, em óbito precoce do paciente sem que o diagnóstico etiológico da doença seja realizado, como aconteceu com a irmã do paciente em questão ${ }^{10}$.

\section{Tabela 3}

Relação entre sinais e sintomas clássicos da síndrome de Zellweger e os apresentados pelo paciente.

\begin{tabular}{lcc}
\hline Sinais e sintomas & $\begin{array}{c}\text { síndrome de } \\
\text { Zellweger }\end{array}$ & Paciente \\
\hline Fronte elevada & + & + \\
Aumento da ponte nasal & + & + \\
Epicanto & + & + \\
Boca triangular & + & - \\
Orelha de formato baixo & + & + \\
Hipotonia profunda & + & + \\
Ausência de reflexos & + & + \\
neonatais & & + \\
Disfagia & + & + \\
Convulsões & + & +
\end{tabular}

Fonte: Os Autores (2019).

O paciente do relato possui mutações no gene PEX1, sendo, portanto, um dos poucos casos de pacientes com síndrome de Zellweger descritos em literatura médica portuguesa, cuja análise molecular ajuda a definir não só o tipo de mecanismo molecular envolvido, mas também abre possibilidade para diagnósticos pré-natal e pré-implantacional. Ademais, o uso de canabidiol para tratamento de pacientes com EZ não teve na literatura médica internacional descrição tão pormenorizada quanto à realizada no seguimento do nosso paciente, visto que apenas houve citação de um paciente tratado com canabidiol em uma grande amostra de pacientes tratados em um estudo multicêntrico acerca de pacientes com epilepsia refratária tratados com essa substância (personal comunication).

\section{CONCLUSÃO}

Não há tratamento definitivo para esta enfermidade, sendo importante tratamento sintomático das crises convulsivas e terapias de reabilitação. Apesar de o mecanismo de ação do canabidiol não ter sido descrito, a terapia com esse medicamento parece ser uma abordagem eficaz no controle de crises convulsivas em pacientes com essa doença, provocando uma redução de $92 \%$ na frequência de crises diárias do paciente. No entanto, não é possível concluir, ainda, melhoras em outros sinais e sintomas.

Por fim, ao se tratar de uma doença autossômica recessiva, com risco de recorrência de $25 \%$, sendo importante o diagnóstico dessa enfermidade para que a família receba o aconselhamento genético adequado, o que não pôde ser observado no caso apresentado, pois o não diagnóstico da primeira filha do casal, que faleceu com suspeita de uma doença genética, mas sem a etiologia estabelecida (portanto sem haver definição de risco de recorrência para orientação do casal), culmina com o nascimento de uma nova criança afetada pela mesma enfermidade. O diagnóstico bem definido possui, agora, importância fundamental para orientação do casal e mesmo tornar possível não só o diagnóstico pré-natal, mas também o diagnóstico genético pré-implantacional, com a seleção de embriões que não fossem portadoras das mutações causadoras da peroxissomopatia.

\section{REFERÊNCIAS}

1. Smitthimedhin A, Otero HJ. Scimitar-like ossification of patellae led to diagnosis of Zellweger syndrome in newborn: a case report. Clinical imaging 2018; 49: 128-130.

2. Heubi JE, Setchell KDR, Bove KE. Long-Term Cholic Acid Therapy in Zellweger Spectrum Disorders. Case reports in gastroenterology 2018; 12: 360-372.

3. Braverman NE, Raymond GV, Rizzo WB, Moser AB, Wilkinson ME, Stone EM, et al. Peroxisome biogenesis disorders in the Zellweger spectrum: an overview of current diagnosis, clinical manifestations, and treatment guidelines. Molecular genetics and metabolismo 2016 ; 117 (3): 313-321.

4. Waterham HR, Ferdinandusse S, Wanders RJA. Human disorders of peroxisome metabolism and biogenesis. Biochimica Et Biophysica Acta (BBA)-Molecular Cell Research 2016; 1863 (5): 922-933.

5. Sani MN, Ahmadi M, Roohani P, Rezaei N. Early Onset Hepatocellular Disease in an Infant with Zellweger Syndrome. Acta Medica Iranica 2017; 55 (4): 268.

6. Ventura MJ, Wheaton $D, X u$ M, Birch D, Bowne SJ, Sullivan LS, et al. "Diagnosis of a mild peroxisomal 
phenotype with next-generation sequencing." Molecular genetics and metabolism reports 2016; 9: 75-78.

7. Wanders, Ronald JA, et al. "Laboratory Diagnosis of Peroxisomal Disorders in the-Omics Era and the Continued Importance of Biomarkers and Biochemical Studies." Journal of Inborn Errors of Metabolism and Screening 6 (2018): 2326409818810285.

8. Klouwer FC, Huffnagel IC, Ferdinandusse S, Waterham HR, Wanders RJ, Engelen M. (2016). Clinical and biochemical pitfalls in the diagnosis of peroxisomal disorders.Neuropediatrics, 47(04), 205-220.

9. Klouwer FC, Berendse K, Ferdinandusse S, Wanders RJ, Engelen M. (2015). Zellweger spectrum disorders: clinical overview and management approach. Orphanet journal of rare diseases, 10(1), 151.

10. Malinescu B, Martius E, Pelin AM. (2015). Violent death in a rare peroxisomal disease-Zellweger syndrome. Forensic science international, 255, 89-95. 